\title{
Glycosylated Haemoglobin in Cord Blood Following Normal and Diabetic Pregnancies
}

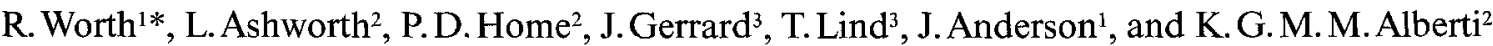 \\ Departments of ${ }^{1}$ Medicine and ${ }^{2}$ Clinical Biochemistry and Metabolic Medicine, University of Newcastle-upon-Tyne, and \\ ${ }^{3}$ MRC Human Reproduction Group, Princess Mary Maternity Hospital, Newcastle-upon-Tyne, UK
}

Summary. Cord and maternal blood samples were obtained at delivery in 25 normal and 14 diabetic pregnancies (13 insulindependent, one gestational). Total glycosylated haemoglobin, measured by the colorimetric thiobarbiturate method ( $\mathrm{mmol}$ hydroxymethylfurfural/mol haemoglobin), was lower in cord than maternal blood (mean 18.7 \pm 1.7 versus 26.5 \pm 2.1 , mean $\pm \mathrm{SD}, p<0.001)$. Glycosylated haemoglobin was higher following diabetic pregnancies, both in cord (diabetic 19.9 \pm 1.6 versus normal $17.9 \pm 1.4, p<0.001$ ) and maternal samples (diabetic $27.7 \pm 1.5$ versus normal $25.6 \pm 2.1, p<0.005$ ). Cord and maternal glycosylated haemoglobin correlated in the normal $(r=0.60, p<0.01)$ but not in the diabetic group $(r=0.02$, NS). Birth weight ratio was higher in infants of diabetic than of normal mothers $(1.10 \pm 0.16$ versus $0.99 \pm 0.13, p<0.05)$ but failed to correlate with cord or maternal glycosylated haemoglobin or, in the diabetic group, with mean blood glucose.

Key words: Glycosylated haemoglobin, cord blood, diabetic pregnancy, normal pregnancy, diabetes, pregnancy, diabetic control.
Many studies have demonstrated an elevation of maternal glycosylated haemoglobin, and hence blood glucose levels, in insulin-dependent and gestational diabetic compared with non-diabetic mothers [1-6]. Attempts to relate these higher maternal levels to indices of fetal morbidity and mortality have shown variable results [1, 5, 7-15]. A more logical approach would be to obtain measurements of fetal blood glucose in utero. Direct sampling is impossible, except in labour, but measurement of glycosylated haemoglobin in cord blood should provide a retrospective measurement of fetal glycaemia in the final weeks of pregnancy. Unfortunately, the presence of fetal haemoglobin [16], part of which is acetylated $[17,18]$, effectively invalidates the commonly used 'rapid' cation-exchange column assays [19, 20]. Column techniques designed to overcome these problems are not suitable for routine use [13].

The colorimetric determination of cord glycosylated haemoglobin provides an alternative which is cheap, easy to perform and free of interference either from fetal haemoglobin, because it measures total glycosylated haemoglobins [21, 22], or from 'fast' glycosylation [23]. This method was therefore used to measure glycosylat-

\footnotetext{
* Present address: Department of Medicine, (Floor P), Royal Hallamshire Hospital, Glossop Road, Sheffield S10 2JF, UK
}

ed haemoglobin in cord blood following normal and diabetic pregnancies. The results were related to established indices of maternal diabetic control and fetal morbidity.

\section{Patients and Methods}

Data were obtained from 39 pregnancies ( 25 normal and 14 diabetic). All individuals gave informed consent to the investigation. The normal women had no family history of diabetes and were free of glycosuria during pregnancy. In the diabetic group, one had gestational diabetes, the remainder being insulin-dependent before the onset of pregnancy.

All mothers received routine antenatal obstetric care, including ultrasound measurements to assess the stage of gestation. Diabetic mothers were seen weekly in the latter part of pregnancy when strenuous efforts were made to optimise blood glucose control, including the use of home blood glucose monitoring. Prior to each clinic visit, diabetic patients collected a series of four pre-prandial capillary samples for subsequent analysis of blood glucose using a glucose oxidase method. All pregnancies resulted in healthy infants and no problems occurred with neonatal hypoglycaemia. The normal mothers produced 15 male and 10 female infants while the diabetic mothers gave birth to 8 male and 6 female infants.

At delivery, cord blood was collected for measurement of glycosylated haemoglobin and blood glucose. Maternal samples for glycosylated haemoglobin were obtained from mothers within $24 \mathrm{~h}$ of delivery. Maternal samples were not available on seven normal patients and the sample from one diabetic mother was unsatisfactory for assay. 


\section{Glycosylated Haemoglobin Analysis}

Samples were taken into glass lithium heparin containers and stored at $4{ }^{\circ} \mathrm{C}$. The plasma was discarded and the red blood cells washed twice in an equal volume of $0.154 \mathrm{~mol} / 1$ saline. The cells were haemolysed by the addition of one to two volumes of distilled water and 0.25 volumes of carbon tetrachloride. Following vigorous shaking for $2 \mathrm{~min}$, the samples were centrifuged at $1500 \mathrm{~g}$ for $20 \mathrm{~min}$ when the clear haemolysate was carefully transferred into a fresh tube. Haemolysate haemoglobin $(\mathrm{Hb})$ concentration was determined by the method of Van Kampen and Zijlstra [24] and samples were adjusted accurately to $50 \mathrm{~g} / 1$ total $\mathrm{Hb}$ by addition of distilled water. One $\mathrm{ml}$ of $0.3 \mathrm{~mol} / 1$ oxalic acid was added to $2 \mathrm{ml}$ of adjusted haemolysate, mixed and immediately placed in a boiling water bath for exactly $60 \mathrm{~min}$. Evaporation was minimised by placing glass marbles on each test tube. After incubation the samples were put into cold water for $2 \mathrm{~min}$ and deproteinisation carried out by addition of $1.0 \mathrm{ml}$ of trichloracetic acid (40\%). Following 'Vortexing' the deproteinised haemolysates were centrifuged for $10 \mathrm{~min}$ at $4^{\circ} \mathrm{C}$ at $1500 \mathrm{~g}$. Two $\mathrm{ml}$ of clear supernatant were carefully transferred to a clean test tube and $0.5 \mathrm{ml}$ of $0.05 \mathrm{~mol} / 1$ thiobarbituric acid reagent added. Samples were mixed and incubated for $60 \mathrm{~min}$ at $40^{\circ} \mathrm{C}$. The colour developed was read spectrophotometrically at $443 \mathrm{~nm}$.

Included in each assay was a sample blank, using distilled water instead of haemolysate, aqueous standard of hydroxymethylfurfural (HMF) at concentrations of 10,30 and $50 \mathrm{mmol} / \mathrm{l}$, together with aliquots from normal and diabetic pooled samples previously stored at $-70^{\circ} \mathrm{C}$. Results are expressed as mmol $\mathrm{HMF} / \mathrm{mol} \mathrm{Hb}$.

Recovery of added HMF (mean \pm SD) was $101.8 \pm 4.0 \%(n=5)$. Between assay variation was $<4 \%$.

\section{Statistical Analysis}

Results were analysed using Student's unpaired t-test and linear regression analysis. Values are expressed as mean $\pm \mathrm{SD}$. The birth weight ratio was obtained from the ratio between actual birth weight and the expected birth weight (fiftieth centile) for sex and gestational age of delivery, according to published tables [25].

\section{Results}

Cord blood glycosylated haemoglobin was significantly higher after diabetic $(19.9 \pm 1.6 \mathrm{mmol} \mathrm{HMF} / \mathrm{mol} \mathrm{Hb})$ than after normal pregnancies $(17.9 \pm 1.4, p<0.001$; Table 1). Cord blood glucose at delivery was similar in diabetic $(4.5 \pm 1.6 \mathrm{mmol} / \mathrm{l})$ and normal pregnancies $(3.9 \pm 0.9 \mathrm{mmol} / 1, \mathrm{NS}$; Table 1$)$.

Significant differences between diabetic and normal women were also observed for maternal glycosylated haemoglobin (diabetic: $27.7 \pm 1.5$ versus normal: $25.6 \pm 2.1 \mathrm{mmol} \mathrm{HMF} / \mathrm{mol} \mathrm{Hb}, p<0.005$; Table 1) although all but three diabetic patients had a glycosylated haemoglobin within our normal non-pregnant range (21.4-29.0 mmol HMF/mol Hb; Fig. 1).

In all pregnancies cord glycosylated haemoglobin $(n=39,18.7 \pm 1.7 \mathrm{mmol} \mathrm{HMF} / \mathrm{mol} \mathrm{Hb})$ was significantly lower than maternal glycosylated haemoglobin $(n=31,26.5 \pm 2.1, p<0.001$; Fig. 1$)$. A correlation existed between cord and maternal glycosylated haemoglobin in the group overall $(r=0.51, p<0.01)$ and also in the normal group $(r=0.60, p<0.01)$ but not in the diabetic group alone ( $r=0.02$, NS; Fig. 2 ).
Table 1. Fetal and maternal glycosylated haemoglobin and cord blood glucose values, gestational age and birth weight in normal and diabetic subjects

\begin{tabular}{|c|c|c|c|c|c|c|}
\hline & \multicolumn{3}{|c|}{$\begin{array}{l}\text { Normal } \\
\text { subjects }\end{array}$} & \multicolumn{2}{|c|}{$\begin{array}{l}\text { Diabetic } \\
\text { subjects }\end{array}$} & \multirow[t]{2}{*}{$p$} \\
\hline & $n$ & & & $n$ & & \\
\hline $\begin{array}{l}\text { Cord glycosylated } \\
\text { haemoglobin } \\
(\mathrm{mmol} \mathrm{HMF} / \mathrm{mol} \mathrm{Hb})\end{array}$ & 25 & 17.9 & \pm 1.4 & 14 & $19.9 \pm 1.6$ & $<0.001$ \\
\hline $\begin{array}{l}\text { Cord blood glucose } \\
(\mathrm{mmol} / \mathrm{l})\end{array}$ & 22 & 3.9 & \pm 0.9 & 14 & $4.5 \pm 1.6$ & NS \\
\hline $\begin{array}{l}\text { Maternal glycosy- } \\
\text { lated haemoglobin } \\
(\mathrm{mmol} \mathrm{HMF} / \mathrm{mol} \mathrm{Hb})\end{array}$ & 18 & 25.6 & \pm 2.1 & 13 & $27.7 \pm 1.5$ & $<0.005$ \\
\hline $\begin{array}{l}\text { Gestational age } \\
\text { at delivery } \\
\text { (weeks) }\end{array}$ & 25 & 39.8 & \pm 1.2 & $13^{*}$ & $37.7 \pm 0.8$ & $<0.001$ \\
\hline Birth weight ratio & 25 & 0.9 & $9 \pm 0.13$ & $13 *$ & $1.10 \pm 0.16$ & $<0.05$ \\
\hline
\end{tabular}

Results expressed as mean $\pm \mathrm{SD}$

* Excludes one premature labour - see text

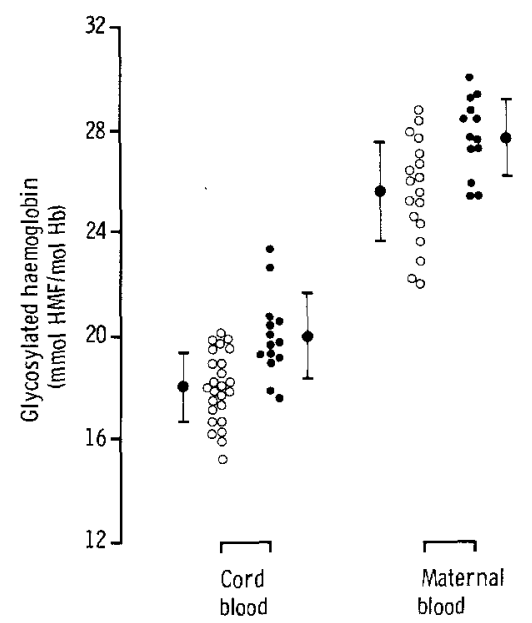

Fig. 1. Glycosylated haemoglobin levels in cord and maternal blood following normal $(O)$ and diabetic (O) pregnancies. Bars indicate mean $\pm \mathrm{SD}$

One diabetic mother delivered a $1460 \mathrm{~g}$ infant prematurely at 30 weeks. After excluding this patient, gestational age at delivery was still lower in diabetic $(37.7 \pm 0.8$ weeks) than in non-diabetic pregnancies ( $39.8 \pm 1.2$ weeks, $p<0.001$; Table 1$)$ and reflected the policy of induction of labour in diabetic pregnancy around 38 weeks of gestation.

Birth weight ratio was higher in the diabetic $(1.10 \pm$ $0.16)$ than in the normal group $(0.99 \pm 0.13, p<0.05$; Table 1) but considerable overlap occurred between the populations. The correlation between birth weight ratio and either cord (Fig.3) or maternal glycosylated haemoglobin was not significant for any group.

Figure 4 shows the distribution of mean maternal blood glucose levels in the final month and final week of diabetic pregnancies. In all but one diabetic mother levels were below $5.5 \mathrm{mmol} / 1$. No correlation was ob- 


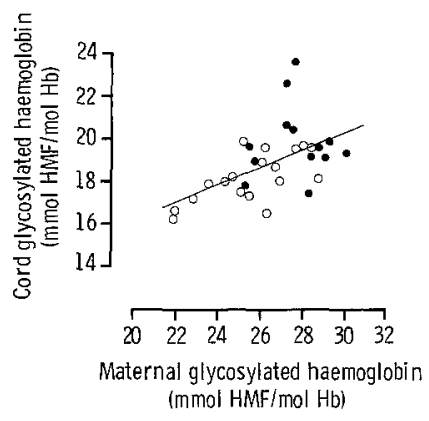

Fig. 2. Correlation between cord and maternal glycosylated haemoglobins. Regression line $\mathrm{y}=0.4+8.3, r=0.51, p<0.01$ (for combined groups). Normal ( $O$ ) and diabetic $(0)$ pregnancies

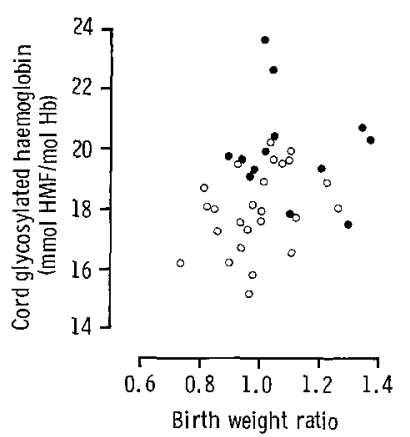

Fig. 3. Correlation between cord glycosylated haemoglobin and birth weight ratio $(r=0.29, p<0.1, \mathrm{NS})$. Normal $(O)$ and diabetic $(\bullet)$ pregnancies

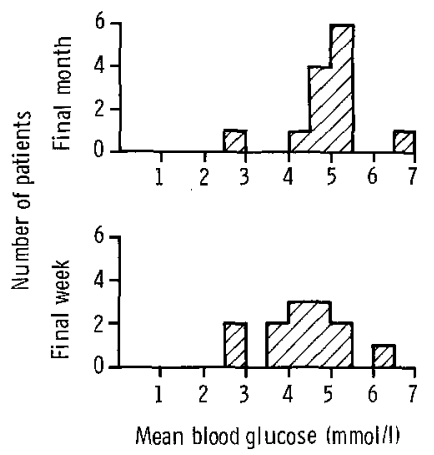

Fig.4. Distribution of mean pre-prandial blood glucose in diabetic mothers in the final month and the final week of pregnancy

tained between mean blood glucose in the final month of pregnancy and maternal glycosylated haemoglobin or birth weight ratio. Cord glycosylated haemoglobin correlated inversely with mean maternal blood glucose in the final month $(r=-0.57, p<0.05)$ but not in the final week of pregnancy $(r<0.005$, N.S. $)$.

\section{Discussion}

Most previous clinical studies of glycosylated haemoglobin in cord blood samples have used either cationexchange resin chromatography [13] or isoelectric fo- cussing techniques [14]. The present study demonstrates that the thiobarbiturate colorimetric assay of glycosylated haemoglobin can be applied to cord blood samples without the need for any special modifications to the method.

Colorimetric analysis has shown considerably lower levels of glycosylation of fetal compared with maternal haemoglobin which would be expected for the following reasons; fetal erythrocytes are produced at a higher rate [26], survive for a shorter time [26] and are exposed to lower levels of blood glucose [27-29] than maternal cells, all factors tending to reduce glycosylation. Also glycosylation of fetal haemoglobin is prevented in part by acetylation $[17,18]$ although this does not affect the dynamics of glycosylation at other sites in vitro [30,31].

The failure to show a correlation between cord and maternal glycosylated haemoglobin in the diabetic group is explicable partly by the fact that the diabetic mothers were well controlled. Thus only three of 13 diabetic mothers had maternal glycosylated haemoglobin values at delivery above the upper limit of the normal non-pregnant range and all except one had mean preprandial blood glucose levels below $5.5 \mathrm{mmol} / 1$ in the last month of pregnancy. However, this cannot be the only reason since a correlation was obtained within the similarly tightly grouped non-diabetic subjects. The present results are similar to those of Fadel et al. [13], using ion-exchange chromatography, who showed higher glycosylated haemoglobin levels in infants of diabetic than normal mothers. Poon et al. [14], using isoelectric focussing, showed a correlation between cord and maternal glycosylated haemoglobin for a combined group of diabetic and normal pregnancies.

Birth weight ratio was higher in diabetic patients but the lack of correlation between this and any of cord or maternal glycosylated haemoglobins or mean blood glucose values was probably due to the relatively 'tight' control of maternal diabetes and to the multifactorial nature of determinants of birth weight [32]. Using different methods other workers $[13,14]$ have likewise failed to correlate cord glycosylated haemoglobin and birth weight ratio. Most previous authors have also failed to obtain a correlation between maternal glycosylated haemoglobin and birth weight ratio [7, 10-14], although some have succeeded $[1,5,8,9,15]$. As would be expected, the poorer the control of maternal diabetes the easier it becomes to obtain such a correlation $[1,5,8,9,15]$.

We are doubtful of the significance of the surprising inverse correlation obtained between cord glycosylated haemoglobin and maternal mean blood glucose in the final month of pregnancy in view of the small numbers, the low level of statistical significance and the absence of any similar correlation with maternal mean blood glucose in the final week of pregnancy. The lack of correlation between maternal glycosylated haemoglobin and mean blood glucose was probably due to the relatively tight grouping of results and the absence of post-prandial blood glucose samples. 
In a recent report Sosenko et al. using the thiobarbiturate colorimetric assay, found similar differences in glycosylation between cord and maternal blood and between normal and diabetic pregnancies [33]. While they also were unable to relate glycosylated haemoglobins to macrosomia they did obtain a correlation between glycosylation in cord and maternal samples in diabetic pregnancies, probably as a result of the larger number of patients studied.

In conclusion, use of the colorimetric assay has demonstrated major differences between the levels of glycosylation of cord and maternal haemoglobins. Despite apparently good control in diabetic pregnancies, fetal and maternal glycosylated haemoglobins were elevated compared with non-diabetic pregnancies, but the elevation could not be related directly to macrosomia.

Acknowledgements. We are grateful to the Scientific and Research Committee of Newcastle Area Health Authority (Teaching) and the British Diabetic Association for financial support. PDH was supported by Novo Industri A/S. We thank Mrs B. Snowdon and Mrs E. Murat for typing the manuscript.

\section{References}

1. Ylinen K, Raivio K, Teramo K (1981) Haemoglobin $A_{1 c}$ predicts the perinatal outcome in insulin-dependent diabetic pregnancies. Br J Obstet Gynaecol 88: 961-967

2. Schwartz HC, King KC, Schwartz AL, Edmunds D, Schwartz R (1976) Effect of pregnancy on haemoglobin $A_{1 c}$ in normal gestational diabetic and diabetic women. Diabetes 25: 1118-1122

3. Paulsen EP, Koury M (1976) Hemoglobin $A_{1 c}$ levels in insulindependent and independent diabetes mellitus. Diabetes [Suppl] 25: 890-896

4. Leslie RDG, John PN, Pyke DA, White JM (1978) Haemoglobin $\mathrm{A}_{1}$ in diabetic pregnancy. Lancet II: 958-959

5. Pollak A, Widness JA, Schwartz R (1979) "Minor hemoglobins": an alternative approach for evaluating glucose control in pregnancy. Biol Neonate 36: 185-192

6. Widness JA, Schwartz HC, Kahn CB, Oh W, Schwartz R (1980) Glycohemoglobin in diabetic pregnancy: a sequential study. Am J Obstet Gynecol 136: 1024-1029

7. Stubbs SM, Leslie RDG, John PN (1981) Fetal macrosomia and maternal diabetic control in pregnancy. Br Med J 282: 439-440

8. Widness JH, Schwartz HC, Thompson D, Kahn CB, Oh W, Schwartz R (1978) Haemoglobin $A_{1 c}$ (glycohaemoglobin) in diabetic pregnancy: an indicator of glucose control and fetal size. $\mathrm{Br} \mathrm{J}$ Obstet Gynaecol 85: 812-817

9. Widness JA, Schwartz HC, Thompson D, King KC, Kahn CB, Oh W, Schwartz R (1978) Glycohemoglobin $\left(\mathrm{HbA}_{1 \mathrm{c}}\right)$ : a predictor of birth weight in infants of diabetic mothers. J Pediatr 92: 8-12

10. Fadel HE, Hammond SD, Huff TA, Harp RJ (1979) Glycosylated hemoglobins in normal pregnancy and gestational diabetes mellitus. Obstet Gynecol 54:322-326

11. Miller JM, Crenshaw C, Welt SI (1979) Hemoglobin $A_{1 c}$ in normal and diabetic pregnancy. JAMA 242: 2785-2787

12. O'Shaughnessy R, Russ J, Zuspan FP (1979) Glycosylated hemoglobins and diabetes mellitus in pregnancy. Am $\mathbf{J}$ Obstet Gynecol 135: 783-790

13. Fadel HE, Reynolds A, Stallings M, Abraham EC (1981) Minor (glycosylated) haemoglobins in cord blood of infants of normal and diabetic mothers. Am J Obstet Gynecol 139: 397-402

14. Poon P, Turner RC, Gillmer MDG (1981) Glycosylated fetal haemoglobin. Br Med J 283:469
15. Vintzileous AM, Thompson JP (1980) Glycohemoglobin determinations in normal pregnancy and in insulin-dependent diabetics. Obstet Gynecol 56: 435-439

16. Huisman THJ, Meyering CA (1960) Studies on the heterogeneity of hemoglobin. I. The heterogeneity of different hemoglobin types in carboxymethylcellulose and in Amberlite IRC-50 chromatography: qualitative aspects. Clin Chim Acta 5: 103-123

17. Schroeder WA, Cua JT, Matsuda G, Fenninger WD (1962) Hemoglobin $F_{1}$, an acetyl-containing hemoglobin. Biochim Biophys Acta $63: 532-534$

18. Schwartz HC, Widness J, Thompson D, Tsuboi KK, Oh W, Schwartz R (1980) Glycosylation and acetylation of hemoglobin in infants of normal and diabetic mothers. Biol Neonate 38:71-75

19. Kynoch PAM, Lehmann H (1977) Rapid estimation (21/2 h) of glycosylated haemoglobin for routine purposes. Lancet 2: 16

20. Simon M, Eissler J (1980) Critical factors in the chromatographic measurement of glycohemoglobin $\left(\mathrm{HbA}_{1}\right)$. Diabetes 29: 467-474

21. Gabbay KH, Sosenko JM, Banuchi GA, Mininsohn J, Fluckiger R (1979) Glycosylated hemoglobins: increased glycosylation of hemoglobin A in diabetic patients. Diabetes 28: 337-340

22. Pecoraro RE, Graf RJ, Halter JB, Beiter H, Porte D (1979) Comparison of a colorimetric assay for glycosylated hemoglobin with ion-exchange chromatography. Diabetes 28: 1120-1125

23. Svendsen PA, Christiansen JS, Soegaard U, Welinder BS, Nerup J (1980) Rapid changes in chromatographically determined haemoglobin $A_{1 C}$ induced by short term changes in glucose concentration. Diabetologia 19:130-136

24. Van Kampen EJ, Zijlstra WG (1961) Standardisation of hemoglobinometry. II. The hemiglobincyanide method. Clin Chim Acta 6: 538-544

25. Thomson AM, Billewicz WZ, Hytten FE (1968) The assessment of fetal growth. J Obstet Gynaecol Br Cwlth 75: 903-916

26. Bratteby LE, Garby L, Groth T, Schneider W, Wadman B (1968) Studies on erythrokinetics in infancy. XIII. The mean life span and the life span frequency function of red blood cells formed during foetal life. Acta Paediatr Scand 57: 311-320

27. Crawford JS (1965) Maternal and cord blood at delivery. Biol Neonat 8: 222-237

28. Spellacy WM, Goetz FC, Greenberg BZ, Ells J (1964) The human placental gradient for plasma insulin and blood glucose. Am J Obstet Gynecol 90: 753-757

29. Cornblath M, Schwartz R (eds) (1976) Metabolic adjustments (homeostasis) in pregnancy. In: Disorders of carbohydrate metabolism in infancy, 2nd ed. Saunders, Philadelphia, pp 29-71

30. Fitzgerald MD, Cauchi MN (1980) Determination of glycosylated hemoglobins in neonatal blood by isoelectric focussing. Am J Haematol 9: 311-317

31. Abraham EC, Stallings M, Cameron BF, Huisman THJ (1980) Minor hemoglobins in sickle-cell heterozygotes and homozygotes with and without diabetes. Biochim Biophys Acta 625: 109-117

32. Stevenson DK, Hopper AO, Cohen RS, Bucalo LR, Kerner JA, Sunshine P (1982) Macrosomia: causes and consequences. J Pediatr 100: $515-520$

33. Sosenko JM, Kitzmiller JL, Fluckiger R, Loo SWH, Younger DM, Gabbay KH (1982) Umbilical cord glycosylated hemoglobin in infants of diabetic mothers: relationships to neonatal hypoglycemia, macrosomia and cord serum C-peptide. Diabetes Care 5:566-569

Received: 23 December 1982

and in revised form: 17 June 1983

Dr. R. Worth

Department of Medicine (Floor P)

Royal Hallamshire Hospital

Glossop Road

Sheffield S10 2JF, UK 